\section{Uma rainha africana mãe de santo em São Luís}

\author{
Pierre Verger
}

Eu quero contar, aqui, um curioso episódio histórico, referente a relações estabelecidas entre a África e o Brasil na primeira década do século XIX. Os vários elementos que o caracterizaram chegaram a meu conhecimento pouco a pouco, durante 52 anos, nas oportunidades de pesquisas orientadas sobre vários assuntos, paradoxalmente alheios à história que vou relatar.

Tive o prazer de viajar ao Daomé (atual República do Benin) em 1936, e de passear em Abomé, sua antiga capital histórica. Visitei, então, o museu instalado nos edifícios dos palácios dos reis daomeanos que mandaram nesta terra entre 1625 e 1900 . Tirei várias fotos de objetos expostos e recolhi, assim, um documento reproduzindo uma tela decorativa ${ }^{(1)}$ pendurada atrás do trono do rei Agonglo $(1789 / 1797)^{(2)}$

\section{A Rainha Na Agontimé, FUNDAdora da CASA daS MINAS EM SÃo LUÍS DO MARANHÃo}

Doze anos depois, em agosto de 1948, tive a oportunidade de falar, em São Luís do Maranhão, com Mãe Anderesa ${ }^{(3)}$ da Casa das Minas ${ }^{(4)}$, onde praticam o culto dos deuses daomeanos. Ela teve a bondade de me comunicar os nomes de certos voduns, pouco conhecidos, bem que citados por Nunes Pereira na sua obra sobre a "Casa das Minas".

Em dezembro do mesmo ano (1948), tendo conseguido uma bolsa de estudos do Institut Français de l'Afrique Noire estive novamente na costa da África para fazer pesquisas sobre os lugares de origem dos orixás e voduns, nagôs e gegês, cultuados no Brasil.

Tentei, entre outras tarefas, conseguir detalhes sobre os voduns indicados por Mãe Anderesa e com esta intenção eu fui visitar a região fronteira do Daomé e do Togo onde vivem os “minas", imigrados da região do Castelo São Jorge da Mina, no Gana atual (antiga Costa do Ouro).

Minha pesquisa nestes lugares foi um fracasso total. Nenhum dos nomes citados pela Mãe de Santo da Casa das Minas era conhecido. Só anos depois entendi a razão deste insucesso, quando percebi que a expressão "negro mina" ou "negro da costa da Mina", encontrada nos documentos dos séculos XVII e XVIII, era a abreviação da expressão "negro da costa situada no leste do Castelo São Jorge de Mina"(5), ou seja, "oriundo da costa dos escravos" situada entre o rio Volta e o rio Lagos, porém não nos lugares visitados em vão, por mim.

Neste mesmo ano de 1948, descobri, felizmente, em Abomé, que estes misteriosos nomes dos voduns da Casa das Minas eram conhecidos como sendo da família real do Daomé e foram identificados sem problema nenhum.

Eis os nomes, classificados na ordem em que me foram dados no Maranhão pela Mãe Anderesa, seguidos de suas identificações em Abomé:

Agongono - que facilmente se julgou tratar de Agonglo.

Savalu ou Azaká de Savalu - que desempenha um papel importante no culto

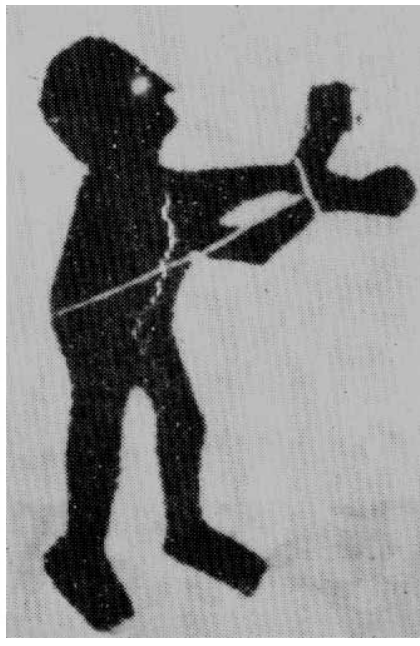

PIERRE VERGER é etnólogo, fotógrafo e historiador. Autor de, entre outros, Fluxo e refluxo do tráfico de escravos entre o Golfo do Benin e a Bahia de Todos os Santos - séc. XVII ao XIX (Editora Corrupio) e Orixás (Ed. Corrupio).

O tftulo original deste artigo $\&$ De uma rainha africana mầ de santo em Săo Luls do Maranhăo e de um trono de rei africano mandado em exflio no Rio de Janeiro. Este texto b capftulo de um livro sobre Sáo Luís do Maranhăo, a ser publicado pela Editora Corrupio.

1 Foto $n=5$.

2 Esta tela ajudou, cinqüenta e dois anos mais tarde, a identificar a tela pertencente ao Museu Nacional da Quinta da Boa Vista no Rio.

3 Foto $n^{0} 1$

4 Nunes Pereira falou a respeito dela em seu livro A Casa das Minas, Rio; Edmundo Correia Lopes, no artigo "O Kpoli de Máe Anderesa", in O mundo portugués, Lisboa; e o livro de Octavio da Costa Eduardo (The negro in the northern Brazil, J. J. N. Y., 1948), no qual ele chama a atenção para a presença de Agongono entre os voduns da Casa das Minas. Ele o identifica com o nome de Agonglo e assinala que aquele de Guezo é totalmente desconhecido pelos participantes do culto dos voduns da Casa das Minas.

5 Verger II, p. 12. 


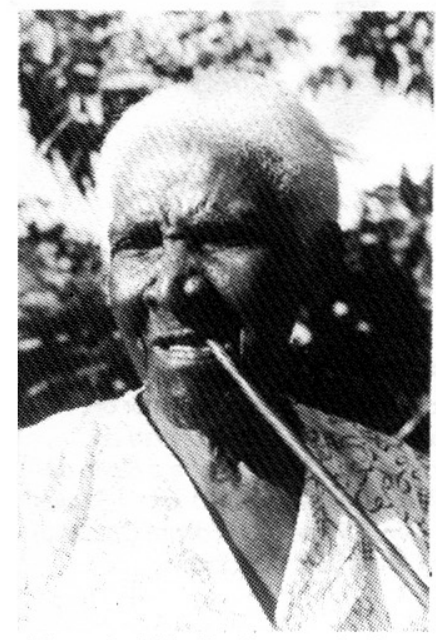

Foto: 1. Mãe Anderesa da Casa das Minas de São Luís do Maranhão.

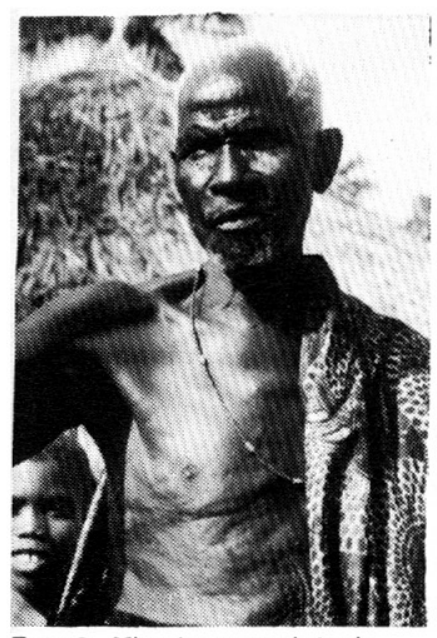

Foto 2. Mivede, sacerdote de Zomadonu em Abomé na África.

6 Foto $n^{2} 2$.

7 Verger I, p. 57.

8 Le Hérissé, p. 312.

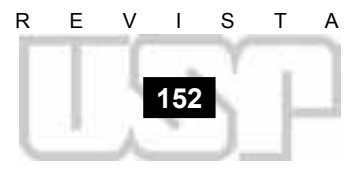

dos Tohossu.

Dadaho - seria Agassu, o vodun dos reis de Abomé.

Bepega - o filho do rei Tegbessu.

Sepazin - a filha do rei Wegbadjá.

Dako - o rei Dakodonu

Bossu - Bossuhon, um nome de Zomadonu.

Joti - um filho de Dadaho.

Koessina - um irmão do rei Agadjá.

Aronovissava - Ahonovi Sava, irmã do rei Dako.

Zomadonu - é o Tohossu, primeiro filho anormal do rei Akabá.

Dossu - seria o rei Dossu Agadjá.

Togpa - é o irmão de Zomadonu.

Desse - o filho do rei Kpenglá.

Dossupê - Kpelu, Tohossu do rei Agadjá.

Apojevô - Agbojahun, filho do rei Tegbessu.

Nani - uma filha do rei Agadjá.

Tossa e Tosse - gêmeos do rei Agadjá.

Naiadono - mãe de Akabá, Agadjá e Hangbê.

Naité - Naité Sedume, mãe do rei Agonglo.

Para uma melhor compreensão da questão, temos que esclarecer que houve doze reis soberanos em Abomé:
Dakodonu - 1625/1650
Wegbadja - 1650/1680
Akabá - 1680/1708
Agadjá - 1708/1740
Tegbessu - 1740/1775
Kpengla - 1775/1789
Agonglo - 1789/1797
Adandozan - 1797/1818
Guezo - 1818/1858
Glegle - 1858/1889
Behanzin - 1889/1894
Aboliagbo - 1894/1900

Assim podemos perceber que nenhum dos voduns citados é posterior ao reinado de Agonglo. Acontece, também, que alguns destes nomes são conhecidos apenas pelos sacerdotes de Abomé. O fato de eu ter encontrado estes nomes no Brasil significou para eles a prova de que existiam, no Novo Mundo, descendentes de membros da família real, mandados fora do Daomé no tempo do tráfico dos escravos. Foi como uma senha para Mivede ${ }^{(6)}$, o sacerdote de Zomadonu, dedicado ao mesmo vodun que Mãe Anderesa da Casa das Minas.

Em Abomé, Mivede é o sacerdote mais importante deste reinado. É ele que detéll. o poder de jurisdição sobre a totalidade dos sacerdotes animistas do lugar.

As notícias que eu trazia do Brasil foram um fator eminentemente favorável para facilitar minhas pesquisas, tendo até publicado, em 1957, um artigo(7) intitulado "Teria o culto dos vodus de Abomé sido importado para São Luis do Maranhão pela mãe do rei Guezo?'”

Porém, para melhor compreensão do assunto, temos que saber um pouco da história do Daomé, baseando-nos em extratos de vários autores que têm escrito sobre a questão que nos interesse.

Um chefe indígena, contando a história do Daomé para Le Hérissé(8), disse: “Adandozan era, entre os filhos primogênitos de Agonglo, quem reunia todas as condições de nascença necessárias para tornar-se rei. Mas seu caráter sanguinário fazia temer sua chegada ao trono. Bem jovem já suprimia os que lhe faziam sombra!

Em desespero de causa, Agonglo perguntou ao Destino, 'Fa', se um outro de seus filhos não dirigiria melhor os negócios do Daomé. 'Fa' designou Guezo! Infelizmente Guezo tinha ainda pouca idade. Apesar disso Agonglo teve fé no oráculo. Resolveu apresentar Guezo como seu sucessor e confiá-lo, como também o Daomé, a Adandozan, persuadido de que os ancestrais protegeriam nosso país e seu rei. Um dia, pois, sentincio seu fim próximo, apareceu a todo seu povo, no mercado de Adjahito, para ditar sua vontade. Em seus braços carregava Guezo; à sua direita estava Adandozan... O Daomé teve a impressão de que tristes acontecimentos iriam produzir-se... 
Adandozan ficou como regente vinte e dois anos e Guezo teve que lhe arrancar o poder. Expulsou-o do trono pois suas atrocidades e suas injustiças tinham enfastiado os daomeanos. Adandozan, que era filho de outra mulher de Agonglo, não tinha hesitado em vender aos mercadores de escravos da costa a mãe de Guezo e uma parte de sua família".

Paul Hazoumé em seu Pacte du sang, nos diz, com efeito, que após a tomada do poder prr Guezo um certo Dossuyévo recebeu em recompensa o posto de intérprete junto a Francisco de Souza, apelidado Chachá $\mathrm{Ajinacu}^{(9)}$, pois, às suas qualidades de coração e fidelidade doméstica, juntava-se o conhecimento da língua portuguesa ${ }^{(10)}$

Quando Guezo quis encontrar sua mãe, a rainha Agontime, vendida aos negreiros por Adandozan, Francisco de Souza, que ficou encarregado das buscas, viu em Dossuyévo homem mais inteligente, mais devotado e mais apto para desempenhar esta missão. Migan Atindébacu (primeiro ministro ao mesmo tempo que carrasco) foi seu adjunto.

Antes da partida dos daomeanos, Chachá Ajinacu e Guezo fizeram pactos com eles para assegurar o sucesso do empreendimento. Os dois enviados tornaram-se, assim, os "irmãos do rei", não duvidando que colocariam, na procura daquela que poderia ser considerada de certa maneira como mãe deles, todo zelo e toda atividade. A primeira viagem foi sem sucesso. Atindébacu e Dossuyévo partiram de novo para outros países em que eram enviados os escravos comprados do Daomé, mas não foram mais felizes, apesar de Francisco de Souza lhes ter fornecido cartas de recomendação para os grandes plantadores daqueles países. Durante a segunda viagem foram para as Antilhas, parando algum tempo em Havana onde, como tinham lhes dito, era enviada a maior parte dos carregamentos de escravos vendidos sob o reinado de Adandozan. Mas os emissários percorreram em vão todas as plantações das Antilhas.

Em seu livro Daomé $e^{(11)}$, a viagem de Dossuyévo nos é indicada como tendo um outro motivo pelo major A. D. Cortez da Silva Curado, que foi comandante do forte português de Uidá de 1885 a 1887: "Logo que Guezo subiu ao trono (1818), enviou ao rei Dom João VI uma embaixada que embarcou para a Bahia a fim de seguir de lá para o Rio de Janeiro. Os embaixadores, após terem esperado três anos um transporte da Corte, retiraram-se para o Daomé sem poder cumprir sua missão. Eu consegui encontrar ainda um dos embaixadores que se chamava Dossuyévo, morto em junho do ano passado.

O primeiro tenente de nossa marinha nacional (portuguesa), José Maria da Silva, que veio em 1886 como comandante da canhoneira Mandavy, me acompanhava na última visita que lhe fiz. Estava cego, movimentando-se com dificuldade e demonstrando um ligeiro cansaço mental, somente pela freqüência com que rememorava o fato de ter ficado na Bahia, como resposta a todas as perguntas que lhe fazia".

Ambroise Dossuyévo, neto do enviado de Guezo, interrogado sobre este assunto, com prazer deu as seguintes indicações: "Meu avô, Dom Antonio Dossuyévo (de acordo com os registros autênticos do Forte português de Uida), teve um papel importante nos comitês de derrubada do rei Adandozan e da intronização de Guezo. É mesmo Na Agontimé, ela própria, que foi encontrada pelo meu avô".

Sabemos, pois, que membros da família do rei Agonglo foram vendidos, após sua morte, como escravos e transportados para um ponto desconhecido das duas Américas.

É um acontecimento quase único na história do Daomé, pois nunca, a não ser Adandozan que perdeu seu trono pelos seus abusos, nenhum rei de Abomé vendeu como escravo um daomeano de Abomé. Eles entregavam seus inimigos aos negreiros mas, como a terra do reino não podia ser alienada, um abomeano não podia ser vendido.

Após suas guerras, os reis do Daomé sempre fizeram o maior dos esforços para recomprar seus soldados, prisioneiros do inimigo, para lhes evitar a escravidão.

Ademais, do exame desta lista percebemos que nenhum dos voduns é posterior ao rei Agonglo, sendo, pois, bem possível que o culto das divindades dos reis de Abomé tenha sido estabelecido na "Casa das Minas" de São Luís do Maranhão por Na Agontimé, viúva do rei Agonglo, mãe de Guezo, que foi enviada para a escravidão por Adandozan e que Dossuyévo e o Migan Atindébacu procuraram por muito tempo através das plantações das duas Américas.

A hipótese, a saber, que Na Agontimé teria trazido o culto dos voduns reais de Abomé a São Luís, foi recentemente reconhecida como sendo verossímil durante o "Colóquio sobre as sobrevivências das tradições africanas nas Caraíbas e na América Latina", que aconteceu em São Luís do Maranhão entre os dias 24 e 28 de junho de 1985 e cujo relatório final declara ${ }^{(12)}$ : "A Casa da Minas foi fundada em São Luís do Mara-

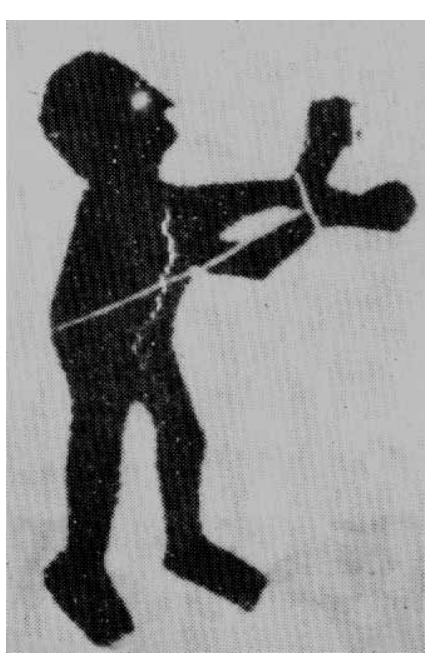

9 Verger I, pp. 11 a 52.

10 Hazoumé, p. 31.

11 Curado, p. 86.

12 Unesco, p. 34.

13 Assim o sugere Judith Gleason no seu livro, página 167: "Seu trono (de Adandozan) foi envolto numa mortaIha como um morto, trazldo a Uldá e mandado através do oceano como presente para o jovem imperador $\mathrm{Pe}$ dro I. Nós (Dossuyévo e Atindébaku) o oferecemos da parte de Guezo ".

14 Inventário levantado por ordem do Conselheiro Secretário de Estado dos Negócios Internos de 11 de julho de 1837. Cartas oficiais de 30 de abril e de 8 de julho de 1839 (Documento $n^{2}$ 95).

15 "África inculta"

a) 1 manipanso ou idolo de madeira b) 1 bandeira com alego ias de Poder $\left(n^{2} 6403\right)$

c) 1 trono de madeira de uma só peça ( $\left.n^{2} 6000\right)$

d) 3 sceptros

e) 1 espada

f) 1 funda

g) 1 armadilha para caça

h) 1 polvarinho

i) 3 mantas

j) 1 esteira

k) 2 abanos de couro

l) 2 alparcatas bo dadas

m) 2 barretes

n) alguns outros ornatos e instrumentos de uso diverso 
Foto 3. Trono no Museu Nacional do Rio de Janeiro.

Foto 4. Trono no Museu Histórico de Abomé na África. nhão, no Brasil, pela rainha Na Agontimé, mãe do rei Guezo, condenada à deportação num acerto de contas no seio da famflia real, antes que seu filho ascendesse ao trono do Daomé em 1818".

\section{O Trono do Rei Adandozan, Mandado Em Exílio na CoRte do IMPERADOR DOM PEDRO I NO RIO DE JANEIRO}

Parece que houve represálias ao bárbaro tratamento infligido por Adandozan a $\mathrm{Na}$ Agontimé, mãe de Guezo. O trono de Adandozan não figura no Museu Histórico de Abomé. Pode-se pensar que, por espírito de retaliação, este trono de Adandozan teria sido mandado por Guezo em exílio no mesmo Brasil onde Na Agontimé foi vendida.

Considerando o caráter sagrado de um trono de rei, Guezo não podia destruí-lo, porém, mandá-lo para uma terra alheia ${ }^{(13)}$. Esta hipótese daria uma explicação sobre a presença de um trono e de uma bandeira daomeanos no Museu Nacional da Quinta da Boa Vista no Rio de Janeiro, já que este museu possui em suas coleções objetos vindos da África no começo do século XIX. Alguns dentre eles figuram em um inventário levantado em 5 de agosto de $1844^{(14)}$ e conservado nos arquivos do Museu Nacional. Este inventário em 14 pontos ${ }^{(15)}$, classificado sob o título de "África inculta", contém objetos de interesse etnológico que, em sua maioria, procedem do Daomé. Alguns dentre eles parecem, além disso, apresentar um caráter histórico: o trono (no 3 da lista publicada nas notas), a bandeira (no 2 ) e provavelmente os três cetros $\left(n^{\circ} 4\right)$ e as sandálias bordadas $\left(\mathrm{n}^{\mathrm{0}} \mathbf{1 2}\right)$.
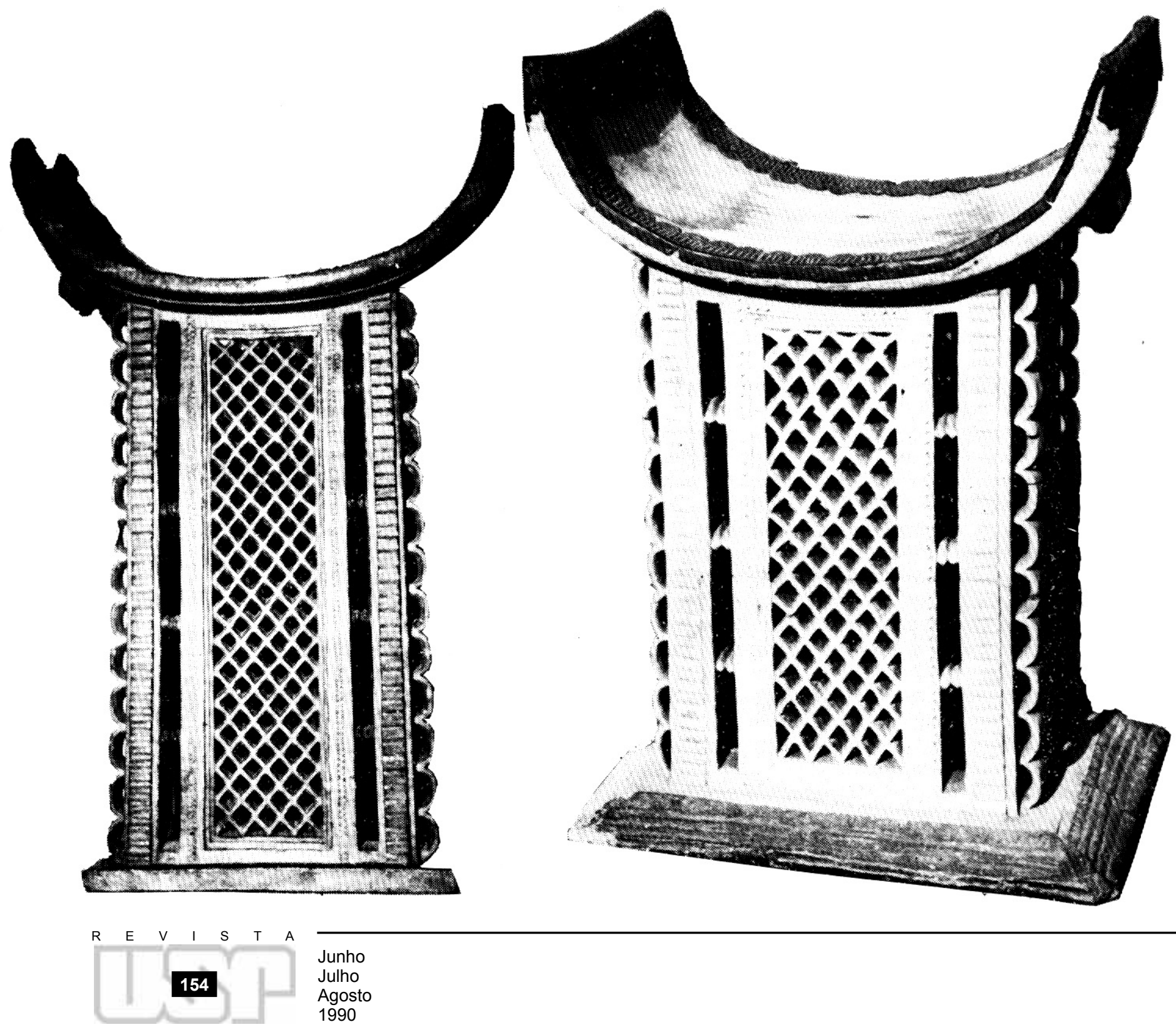
O trono ${ }^{(16)}$, classificado com o número 6000 do inventário, é de um estilo certamente daomeano. A ficha do Museu do Rio de Janeiro contém somente a menção "Trono de régulo africano, de madeira esculpida", mas basta compará-lo com aquele do rei Kpengla (1774-1789) ${ }^{(17)}$ para se perceber que o assento real conservado no Rio de Janeiro é a réplica (com diferença em altura) daquele exposto no Museu Histórico de Abomé.

Além do interesse desta identificação, é necessário levar em conta também a antiguidade daquela peça, que, veremos mais adiante, remonta provavelmente a 1797, enquanto que somente um dos onze tronos expostos no museu de Abomé, o de Agonglo (1789-1797), é mais antigo que o exposto no Rio de Janeiro, pois, dentre aqueles onze tronos, somente os últimos cinco são autênticos; os originais dos primeiros seis desapareceram durante o incêndio que o rei Behanzin mandou atear em Abomé para destruir os palácios reais e a cidade em 16 de novembro de 1892, véspera da tomada da capital do Daomé pelas tropas do general Dodds.

Podemos ver a este respeito a narração do capitão Aublet ${ }^{(18)}$ e a que um "chefe indígena" fez a Le Hérissé(19) - sobre a "perda da maioria das lembranças históricas desaparecidas no incêndio".

Aboliagbo, quando reinava em Abomé entre 1894 e 1900, mandou refazer os seis tronos queimados, pelos escultores oficiais dos reis de Abomé, estabelecidos na aldeia de Banamé, perto de Cové. O segundo objeto da lista, número 6403 do inventário de 1844, "bandeira com motivos alegóricos de poder"(20), é, como veremos, o mais antigo exemplar de tapeçarias feitas no Daomé pelo processo que consiste em decorar uma tela branca ou preta com motivos de tecido colorido, cortado e aplicado em cima destas telas de fundo. Não se trata neste caso presente de uma tapeçaria, mas de uma bandeira, onde os motivos são aplicados nos dois lados da tela.

Esta bandeira consiste em uma peça de tecido de um metro por dois aproximadamente, de cor bege, com a textura parecida com a do pano de saco. Está coberta de motivos em tecido preto representando guerreiros inimigos prisioneiros com as mãos atadas, cabeças cortadas cujo pescoço tem um debrum vermelho para representar o sangue; no centro, figura um daomeano portador de uma cabaça contendo duas cabeças cortadas; tudo isto acompanhado de sabres curvos ou espadas retas.

Estas telas decorativas existiam no Daomé há muito tempo, mas nenhuma das antigas telas resistiu à ação do tempo, aos insetos e incêndios. As que estão expostas no Museu de Abomé, refeitas periodicamente, não datam senão de alguns decênios. A que está conservada no Museu do Rio de Janeiro teve, pelo contrário, melhor sorte e ficou admiravelmente conservada desde o começo do século XIX até os dias de hoje.

É interessante notar que o motivo do cativo nagô com as mãos atadas, da tela do Museu Nacional do Rio de Janeiro, é idêntico ao que está na tela fotografada em Abomé no ano de 1936, um fato que descobri recentemente, em 1988, quando tive que escolher documentos para uma exposição organizada durante a celebração do centenário da abolição da escravatura no Brasil.

Sabemos que a partir do rei Agonglo (1789-1797), a exclusividade do trabalho de aplicação sobre tecido foi dada à família Yémadjé. $\mathrm{O}$ chefe atual desta família de alfaiates decoradores, Mènogbé Yémadjé, vendo em 1955 a fotografia desta bandeira, e atualizando os fatos, nos explicou há pouco tempo espontaneamente: "Quando um território é conquistado, os escravos são conduzidos assim, e são decepados (para honrar os reis mortos)"'(21).

Mènogbé Yémadjé nos explicou, durante a entrevista em que lhe mostramos a reprodução da bandeira confeccionada por um de seus ancestrais, como seu avô, na sexta geração, tornou-se fornecedor oficial do rei Agonglo para a decoração de seus guardasóis, bonés, tapeçarias, bandeiras e painéis de telas:

"Agonglo tinha se casado com Na Agontimé filha de Gan Yambaku, chefe da aldeia de Tendji, e percebera no filho primogênito do mesmo, um certo Blè, um hábil alfaiate e fabricante de bonés. Agonglo pediu ao pai que lhe desse seu filho. Gan Yambaku recusou declarando que era seu braço direito. No dia seguinte, Agonglo enviou muitas riquezas ao chefe da aldeia de Tendji, tecidos, bebidas, dinheiro em abundância, tudo isso como se se tratasse de obter uma filha em casamento. Oito homens eram portadores daquelas riquezas. Gan Yambaku surpreso perguntou: 'O rei Agonglo falou em esposar mais uma de minhas filhas?'. 'Não', lhe respoderam os portadores, 'ele quer esposar o rapaz'.

Gan Yambaku foi, pois, obrigado a enviar Blè para Abomé. O rei vendo-o chegar declarou: Zan ma kua o yé nõ djé ho ta a, significando: 'Se não se fizer noite, a sombra

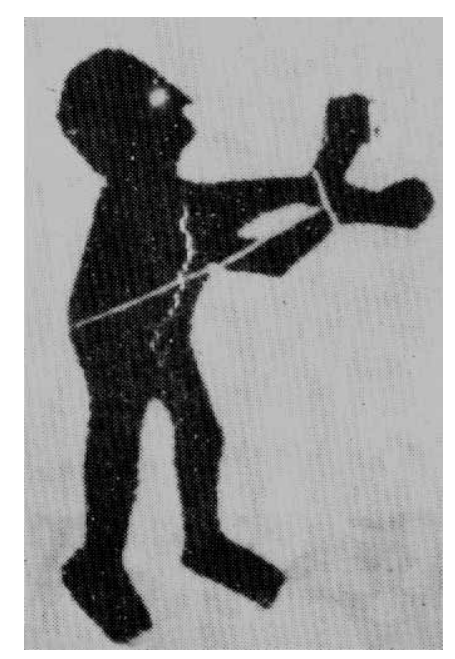

16 Foto $n^{2} 3$

17 Foto $n^{2} 4$

18 Aublet, p. 322.

19 Le Hérissé, p. 348.

20 Foto $n^{2} 5$.

21 Que estes motivos sejam bem daomeanos é o que, além disso, é ates. tado por viajantes do século passado. D ter om escreve: "No alto do muro destacavase um portador de estandarte, tendo como emblema um crânio dentro de uma cabaça apoiada sobre três outros crânios. Em volta do pátio havia várias bandeiras de todas as cores,

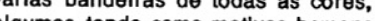
motivos homens cortando cabeças $\theta$ outros amarrando prisioneiros" (Forbes, vol. II, p. 36). Richard Burton, descrevendo o guarda-sol do Daomé em 1853, indica que os principals motivos decorativos eram "facas e cabeças decapitadas, recortadas em tecido ecaturostuadas sobre os painéis do guardasol" (Burton, vol. l, p. 137). Skertchly explica que os jovens "guerreiros" recebiam do rei um guarda-sol todo branco, e que năo tinham o direito de decorá-lo a năo ser apos ter abatido um inimigo. Eles ornavam, entro os painéls navam, guarda-sol, altridamo com a reproduçăo de uma cabeça $\theta$ com a de um sabre (Skertchly, p. 194). 
Foto 5. Tela no Museu Histórico de Abomé na África. não descerá sobre o telhado' (não há efeito sem causa). Esta frase encurtada está na origem do nome de Yèmadjé.

O rei Agonglo não esposou o rapaz, mas lhe deu oito mulheres como esposas e oito homens como aprendizes de alfaiate".

Em 1810, Adandozan enviava uma embaixada ao Príncipe Regente de Portugal. Era a quarta das embaixadas, da qual encontramos traços, que tinham sido enviadas pelos reis do Daomé aos de Portugal ${ }^{(22)}$.

No dia 30 de janeiro de 1811 , os quatro emissários do rei do Daomé chegavam à Bahia como portadores de um presente ${ }^{(23)}$ enviado por Adandozan ao Príncipe Regente de Portugal. Ele enviava também uma jovem negra ao Conde dos Arcos, governador da Bahia. Este agradeceu ao soberano daomeano com uma carta ${ }^{(24)}$, onde lhe avisava o envio para o Daomé de um casal de galgos, macho e fêmea, como também de outros dois cães, macho e fêmea. Tudo nos leva a crer que "o trono em madeira de uma só peça" e "a bandeira alegórica de poder" constituíam o presente enviado por Adandozan ao Príncipe Regente de Portugal.

Baseamos esta hipótese nas seguintes considerações:

Tais objetos eram fabricados exclusivamente para os reis do Daomé;

Este presente era "real" e não poderia ser feito se não de soberano a soberano;

Estas peças já se encontravam no palácio imperial do Brasil no tempo do imperador Dom Pedro II, neto do rei D. João VI (ex-Príncipe Regente);

Ninguém cogitava no começo do século XIX em colècionar "objetos de arte" da "África inculta";

Somente a embaixada de 1811 tinha encontrado a Corte de Portugal instalada no Brasil. A família real tinha vindo refugiar-se, em 1807, da invasão de Portugal pelas tropas de Napoleão. As embaixadas precedentes datam de 1750, 1795 e 1805; a primeira não ultrapassou a Bahia e as outras duas tinham ido até Lisboa. A última dentre elas, chegada em 30 de janeiro de 1811 na Bahia, foi retida naquela cidade, de acordo com as instruções recebidas da Corte do Rio de Janeiro, e somente os presentes e a carta de Adandozan tinham sido retransmitidos.

Os embaixadores tiveram que esperar até o dia 17 de outubro de $1812^{(25)}$ para reembarcarem com destino ao Daomé, tendo recebido "em testemunho da Real Magnificência, uma bandeja com um aparelho completo de fazer chá".

A razão desta longa demora foi motivada pelo fato de que o governo do Brasil hesi-

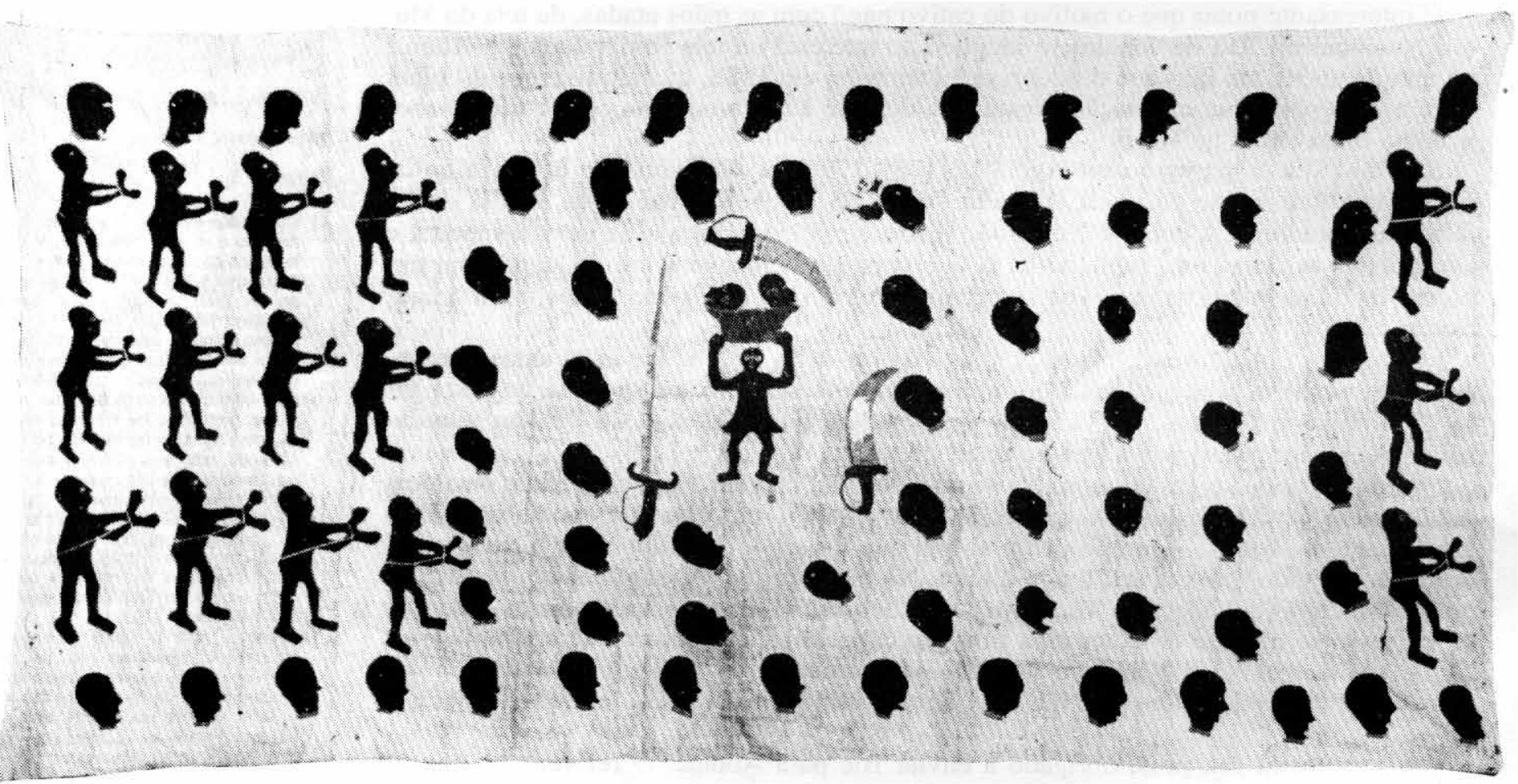

$\begin{array}{llllll}R & E & V & \text { I } & S & T\end{array}$ 
tava em abolir completamente o tráfico de escravos, cujos braços eram ainda indispensáveis à economia do país. Esperava-se no Rio de Janeiro poder continuar com o tráfico em Uidá, malgrado pressão do governo britânico que se opunha.

$\mathrm{O}$ tratado de aliança e de amizade anglo-português de 19 de fevereiro de 1810 restringia àquele único porto de Uidá o tráfico ao norte do Equador, e não deveria ser aboiido, em princípio, naquele local, após a Convenção e o Tratado de 1815 assinados entre as mesmas altas partes contratantes.

Haveria uma outra explicação a respeito da origem desse trono exposto no Museu Nacional do Rio de Janeiro. Esse trono poderia ter sido aquele do próprio Adandozan, expedido para fora do Daomé por seu sucessor, Guezo, em represália ao envio para a escravidão no Brasil de sua mãe Na Agontimé.

Vimos mais acima que o "chefe indígena", ao falar com Le Hérissé de Adandozan, o apresentava como sendo Regente do Reino de Abomé durante a minoridade de Guezo; este teria sido designado para sucedê-lo no trono.

Adandozan foi de fato o sucessor de Agonglo em 1797; foi destronado em 1818 por Guezo, seu irmão do lado paterno. Mas, observa Edouard Dunglas ${ }^{(26)}$, "esse rei deixou uma péssima lembrança nas tradições de Abomé, em razão de sua grande crueldade. Os daomeanos recusam a contá-lo dentre o número de seus reis e no Museu Histórico de Abomé o trono de Adandozan não figura entre aqueles da dinastia. A razão é bem simples: não é por aversão pessoal contra ele, ou ainda a conseqüência da indignação provocada pelas excentricidades e crueldades que lhe são conferidas; se os príncipes, homens ilustres dignitários de Abomé, enegreceram sistematicamente a memória do rei Adandozan, era sobretudo para cortejar o rei Guezo, usurpador do trono de seu irmão. A difamação do príncipe expulso legitimava a usurpação".

Maurice Ahanhanzo Glelê, descendente de Guezo na quinta geração, confirma ele próprio ${ }^{(27): ~ " P o d e-s e ~ e s t i m a r ~ c o m o ~ s e n d o ~ e x c e s s i v a ~ v o n t a d e ~ d o s ~ r e i s ~ e ~ d o s ~ h i s t o r i a d o r e s ~}$ no sentido de apagar para sempre o nome de Adandozan da memória dos abomeanos". Em seguida, ele lembra que o tráfico de escravos foi abolido pela Grã-Bretanha em 1807 e por Portugal em $1815^{(28)}$ Isso provocou o abandono dos fortes português, francês e inglês ${ }^{(29)}$ de Uidá e privou o rei de uma parte dos recursos provenientes da venda de escravos. "O marasmo econômico que disso resultava faz com que sejam compreendidas as razões de sua substituição por Guezo."

Maurice Ahanhanzo Glelê observa ${ }^{(30)}$ que "talvez seja possível dissipar a espessa sombra que recobre o reinado de Adandozan, reportando-se aos documentos que existem nos arquivos de Portugal e Brasil. Testemunhos relativos às altercações de Adandozan com o forte português de Uidá e a missão oficial enviada à Bahia (20 de fevereiro de 1805) poderão permitir o esclarecimento da questão ${ }^{(31)}$.

Esse trono do rei Adandozan, "que não figura dentre aqueles expostos no Museu Histórico de Abomé", poderia ser o trono que está atualmente exposto no Museu Nacional do Rio de Janeiro.

Judith Gleason escreve, ao retratar a vida romanceada de $\mathrm{Na}$ Agontimé((32) que "assim que os emissários de Guezo, Dossuyévo e Atindébaku, chegaram na Casa das Minas para procurar por Na Agontimé e levá-la de volta a Abomé" explicaram a ela que "Guezo tomara todas suas precauções para que a memória de Adandozan não fosse perpetuada. Confiscara tudo o que lhe pertencera, todos os objetos e insígnias que pudessem lembrar a sua passagem pelo trono e que o próprio trono de Adandozan fora encoberto por um lençol branco e preto, como se fora um cadáver, e transportado a Uidá para ser expedido ao Brasil. Escoltado pelos emissários de Guezo, o trono fora oferecido como presente do rei Guezo para a coroação do jovem imperador Dom Pedro I".

Tal hipótese de Judith Gleason parece digna de atenção. As datas são válidas. A coroação de Dom Pedro ocorreu em 1 de dezembro de 1822, ou seja, quatro anos após a ascensão de Guezo ao trono do Daomé.

Ademais, poder-se-ia pensar que esse trono é o mesmo do qual fala Maria Graham ${ }^{(33)}$ em seu diário, no dia 14 de agosto de 1823 ? "Fui com o Sr. Plasson, francês muito inteligente, ao museu... (aonde) encontra-se o trono de um príncipe africano; $́$ de madeira lindamente lavrada."

Esse drama do exílio de Na Agontimé encerra-se gloriosamente, um pouco "à moda francesa", que termina tudo com canções: o Grêmio Recreativo de Arte Negra Escola de Samba Quilombo do Rio de Janeiro tomou, de fato, o tema de enredo para o Carnaval de 1984 em "O Xaxá de Ajudá e a Rainha Mina do Maranhão". Ali, os autores Neguinho Jóia, Feliciano e Henrique - proclamam:

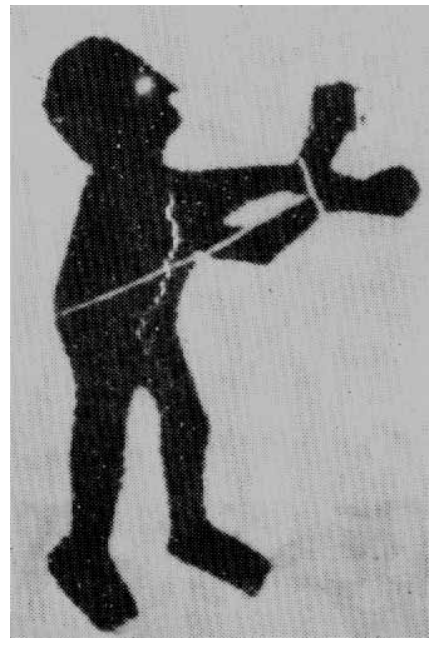

22 Verger II, cap. VII.

23 AEB 112, f. 134.

24 AEB 167, f. 127.

25 AEB 113, f. 424.

26 Dunglas, p. 35.

27 Glele, p. 125.

28 Verger II, pp. 293 a 312.

29 Verger II, pp. 245-246.

30 Glele, p. 125, nota 11.

31 Verger II, p. 271.

32 Gleason, p. 267.

33 Graham, p. 305.

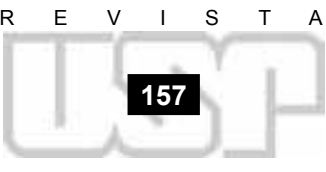


“Mãe África

Terra da soberana Agontimé

Mãe de Guezo

E mulher de Agonglo

Rei do antigo Daomé

Que um certo dia

Adandozan

Se apoderou do trono

$E$ vendeu a rainha

Pra São Luís do Maranhão

Mesmo escravizada

A rainha difundiu

O culto do vodu Zomadone

Que deu origem

Â Casa das Minas do Brasil"

Em seguida, os autores celebram a memória daquele que foi o maior traficante de escravos de todos os tempos:

\author{
"Enquanto aqui isso se passava \\ O brasileiro Félix de Souza prosperava \\ Lá em Daomé \\ Incrementava aquela Nação \\ Se tornando o pioneiro \\ Do povo Tambom"
}

Tambom era a alcunha dada no Gana, ex-Costa do Ouro, aos descendentes de "brasileiros", isto e, os negros alforriados que retornaram à África.

"Ao rei Guezo impôs sua influência

Desenvolveu toda sua experiência

Que o rei chegou lhe outorgar

O título de 'Xaxá do Ajudá"

O rei Guezo, fornecedor de escravos, e Xaxá de Souza, que os expedia e vendia ao Brasil, curiosamente ambos tornam-se, assim, aos olhos de descendentes de africanos, os símbolos da afro-brasilidade.

\title{
BIBLIOGRAFIA
}

AUBLET, Ed. La guerre au Dahomey (1888-93). Paris, 1984.

BURTON, R. F. A mission to Gelele, King of Dahomey. London, 1864.

CORTEZ DA SILVA, A. D. Daomé. Lisboa, 1888.

DUNGLAS, E. “Contribuition à l'Histoire du Moyen-Dahomey", in Études Dahoméennes XX. Porto Novo, 1957. EDUARDO, O. da Costa. The negro in northern Brazil. N. York, 1948.

FERRETTI, S. Figueiredo. Querebetan de Zomadonu. São Luís, 1985.

FORBES, F. E. Dahomey and the Dahomans. Londres, 1851.

GLEASON, J. Agotimé, her legend. Nova York, 1970.

GLELE, M. A. Le Daome. Paris, 1974.

GRAHAM, Maria. Diário de uma viagem ao Brasil. São Paulo, 1956.

HAZOUME, P. Le pacte du sang au Dahomey. Paris, 1956.

HERSKOVITZ, M. J. Dahomey, an anciest west African Kingdon. N. Y., 1936.

IFAN. Mémoire no 27. Dakar, 1953.

LABAT, R. P. Voyage du Chevalier des Marchais. Amsterdam, 1721.

LE HÉRISSÉ, A. L'Ancien Royaume du Dahomey. Paris, 1911.

LOPES, E. C. "Kpoli de Mâe Anderesa", in O mundo português. Lisboa.

MUSEU NACIONAL. Doc. 95, Inventário. Rio de Janeiro, 1839.

PEREIRA, Nunes. A Casa das Minas.

PIRES, V.F. Viagem no Daomé. São Paulo, 1957.

RECLUUS, E. Nouvelle Géographie Universelle. Paris, 1887.

SKERTCHLY, J. A. Dahomey as it. Londres, 1874.

UNESCO. Rapport final colloque sur les survivances des traditions religieuses africaines dans les Caraibes et en Amérique Latine. São Luis do Maranhão, 1985.

VERGER, P. (I). "Le culte des voduns d'Abomey aurait-il été apporté à Saint Louis du Maranhão par la mère du roi Ghézo", in Mémoire de IIFAN no 27. Dakar, 1953.

VERGER, P. (II). Fluxo e refluxo do tráfico de escravos entre o Golfo do Benin e a Bahia de Todos os Santos. S. Paulo, 1987. 